\title{
COMPARISON OF ANTIBACTERIAL EFFECT AND SMEAR LAYER REMOVAL OF HERBAL VERSUS TRADITIONAL IRRIGANTS - AN IN VITRO STUDY
}

\author{
Elsaeed A.Elhafez * and Mahmoud M. Badr *
}

\begin{abstract}
Background: Elimination of endodontic pathogens through appropriate cleaning and shaping procedures along with strict isolation protocols is of great significance for disinfecting this complex anatomy of the root canal configuration. Persistent periradicular lesions are usually associated with Enterococcus faecalis. Various compounds are being utilized as irrigants throughout the cleaning for shaping procedures to accomplish the favorable level of disinfection.
\end{abstract}

Aim: The current study aim to compare the anti-microbial efficiency of Salvadora Persica (Miswak-Siwak) and Chitosan in comparison with Sodium Hypochlorite ( $\mathrm{NaOCl}$ ). Also comparing their ability to eradicate the smear layer.

Materials and Methods: Seventy-five extracted human single rooted teeth were cut at the cemento-enamel junction (CEJ). The roots were instrumented by $\mathrm{k}$-files till size 25 . These teeth were sterilized and then contaminated by Enterococcus Faecalis in brain heart infusion for 3 weeks. The samples were divided into 4 groups (S.Persica, Chitosan, $\mathrm{NaOCl}$ and normal saline). The bacterial count was calculated using colony forming unites (CFU).Then, the roots were split longitudinally and examined by SEM for evaluation of smear layer removal in coronal, middle and apical thirds.

Results: Regarding antibacterial effect, $\mathrm{NaOCl}$ showed the least mean values, however saline showed the highest,followed by S. Persica and Chitosan. Regarding smear layer removal ,S.Persica showed the least values. $\mathrm{NaOCl}$ and positive control showed the highest values,followed by Chitosan.

Conclusion: The use of herbal alternatives as root canal irrigating solutions might prove to be advantageous considering several unfavorable properties of $\mathrm{NaOCl}$.

KEY WORDS: Antibacterial efficacy, Chitosan, Enterococcus faecalis, Root canal irrigation, S.Persica, $\mathrm{NaOCl}$.

\footnotetext{
* Lecturer of Endodontics, Faculty of Oral and Dental Medicine ,Future University- Egypt.
} 


\section{INTRODUCTION}

Elimination of the pathogenic microflora from the entire root canal system during the endodontic therapy is one of the main goals of endodontic treatment. Microbial organisms play an important role in the development of inflammation and necrosis of the pulpal tissues and formation of periapical lesions. ${ }^{(1)}$ Elimination of microorganisms is mandatory, however its difficult due to the anatomical complexities and irregularities of the configuration and the inability of the enlarging instruments to touch all the dentinal canal walls leaving un-touched areas, thus the decision making of mechanical enlarging technique along with the chemical disinfecting method are of great significance for proper disinfection and eradication of microorganisms from the entire configuration without impairing the healing capabilities that is crucial for the accomplishment of long term success. (2). Various multifunctional irrigants were utilized to accomplish the ideal disinfecting impact from the time $\mathrm{NaOCl}$ was presented in early $90 \mathrm{~s}^{(3)}$.

A nebulous, sporadic coating appeared to adhere to dentine after instrumentation. It comprises organic and inorganic components. The organic component is usually a collection of pulpal and bacterial debris whereas the inorganic component is mainly made of dentinal debris. ${ }^{(4)}$.

$\mathrm{NaOCl}$; the gold standard endodontic irrigation solution as a result of its potent antibacterial efficiency capability to disintegrate pulp tissues. Also, its use should be cautious as it possesses some drawbacks like being very irritant to the tissues beyond the apex, toxicity and reducing the elastic modulus of dentin ${ }^{(5)}$.

Chitosan is originally a type of saccharides derived from chetten; the second most abundant poly-saccharide in the world, after cellulose. The covalent immobilization on dentinal collagen enhance the remineralization of the demineralized dentin. Moreover, it enhances the dentin resistance to collagenase degradation. It is natural, biocompatible, bio-degradable, antibacterial and nontoxic. ${ }^{(6) .}$

Salvadora Persica is a medical plant that been used for oral hygiene measures worldwide. It's a biting block utilized for brushing aids. Furthermore, it is produced using sweet-smelling base little shrubbery. Numerous investigations exhibited the concentrates of this medical plant can aid to prevent the formation and accumulation of plaque with some antifungal impacts. Studies consider Siwak to have some characteristic synthetic mixes with good antimicrobial properties ${ }^{(7)}$.

In this manner, it is significant to reveal an insight into the viability of characteristic herbal irrigation solutions in comparison with the novel gold standard $\mathrm{NaOCl}$.

\section{MATERIALS AND METHODS}

\section{Sample Preparations}

In this study, a total of 75 teeth with only one completely mature intact root and closed apical foramen was used .Then decoronated to the cementoenamel junction utilizing sharp saw cut with abundant cooling for proper strandardisation of a $16 \mathrm{~mm}$. A sterile file size 10 was passed from orifice by the classic quarter turn and pull till the file end was seen protruding from the apex to check patency of the canal and then obtaining the tooth length by retrieving the file till its flush with the apex . After reducing one $\mathrm{mm}$ from this reading, WL was obtained. Subsequent files till \#25 were used to enlarge the apical portion of roots .While preparing the teeth, normal saline was used to irrigate the canals during preparation.

\section{Sample Sterilization:}

Teeth had been sterilized using gamma radiation (Cobalt 60 irradiators with dose rate of $1.774 \mathrm{KGY}$ with total dose of $25 \mathrm{KGY}$ ). 


\section{Bacterial infusion:}

$50 \mu \mathrm{L}$ of Enterococcus F. was introduced into every tooth utilizing a specific dropper. Then they were put in sterile tubes and held vertically in perforated trays for 21 days in an incubator at $37^{\circ} \mathrm{C}$, with renewing the medium every 3 days. ${ }^{(8)}$

\section{Grouping of samples}

Regarding the type of irrigant, all specimens have been divided into4 groups

GpA: Alcoholic extract of $\operatorname{Siwak}(12.5 \%)$ "20 teeth". GpB:Chitosan(0.2\%) “20 teeth”.

GpC: $\mathrm{NaOCl}(5.25 \%)$ "20 teeth".

GpD:Saline (control positive) “15 teeth".

\section{Preparation methods:}

1- Siwak-Miswak: concentrates were set up by taking $750 \mathrm{gm}$ of biting S. Persica blocks, then wiped them off using a blade. Afterward crushing them to form a fineform and including $140 \mathrm{ml}$ of $70 \%$ ethyl alcohol to 50 grams of the fine crushed form into clean specific jug, remain 7 consequent 24 hours, filtering utilizing a special framework.

2- Chitosan: A suspension was readied utilizing $0.2 \mathrm{~g}$ crushed fine form. Then added to $100 \mathrm{ml}$ $2 \%$ acitic a., then blend had been mixed three hours ${ }^{(9)}$.The suspensions were ready after 7 days then spared at fridge.

3- Root canal preparation: Universal ProTaper Ni-Ti rotary files were used in a crown-down manner for root canal preparation with a 16:1 reduction hand piece that was powered by a torque-controlled electric motor; at a rotational speed of $300 \mathrm{rpm}$ and a torque-control of $2.6 \mathrm{~N} / \mathrm{cm}$.

After each instrument use, the grouping, irrigation was performed by $3 \mathrm{ml}$ of the irrigants.

\section{Evaluation methods}

\section{Bacterial counting}

Sampling done by \#25 absorbent p.pin each root canal. Then transported to an experimental tubing with one $\mathrm{ml}$ distillated water. Then paper points were carefully homogenized by vortexing the tube $40 \mathrm{sec}$. Successive various concentrations were produced. A no. $2 \mathrm{ml}$ of every concentrate had been plated on the BHI. Then the process of incubation was performed at almost body temperature in 2days. Colony Counting procedures were done after the brooding had been finished .Bacterial load was quantified as colony forming units (CFU)/ $\mathrm{mL}$ using an automatic colony counter.

\section{SEM Evaluation}

By a metallic disk, 2facing vertical slots prepared in the samples with copious watering and cautious to avoid grooving into the root, afterwards each root was split in two halves with a chisel. The samples were properly placed on a frame and observed with electron microscopy. Smear layer assessment was done at the apical, middle and cervical thirds of every split. Evaluation was done with the novel3point method of scoring. ${ }^{(10)}$

\section{RESULTS}

\section{Antimicrobial action :}

There was a significant statistic difference between $\mathrm{NaOCl}$, Chitosan, Siwak and saline groups. Also, between $\mathrm{NaOCl}$ and both Miswak and Chitosan groups with no differences in-between both Siwak and Chitosan groups. Positive control group showed the highest values then Siwak and Chitosan groups, whilst $\mathrm{NaOCl}$ group showed the least values.

\section{Bar charts representing antibacterial effect}

\section{Smear Layer analysis:}

There was significant statistic differences between $\mathrm{NaOCl}$, Citosan, Siwak and control positive 

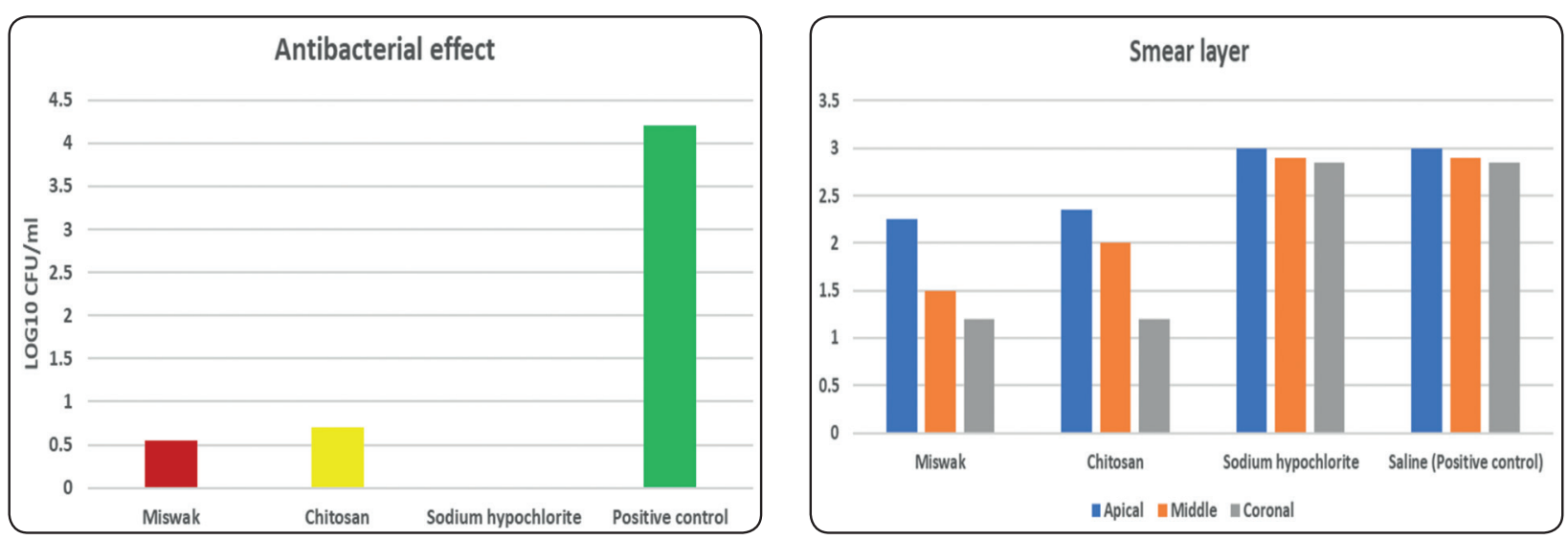

Bar charts representing antibacterial effect
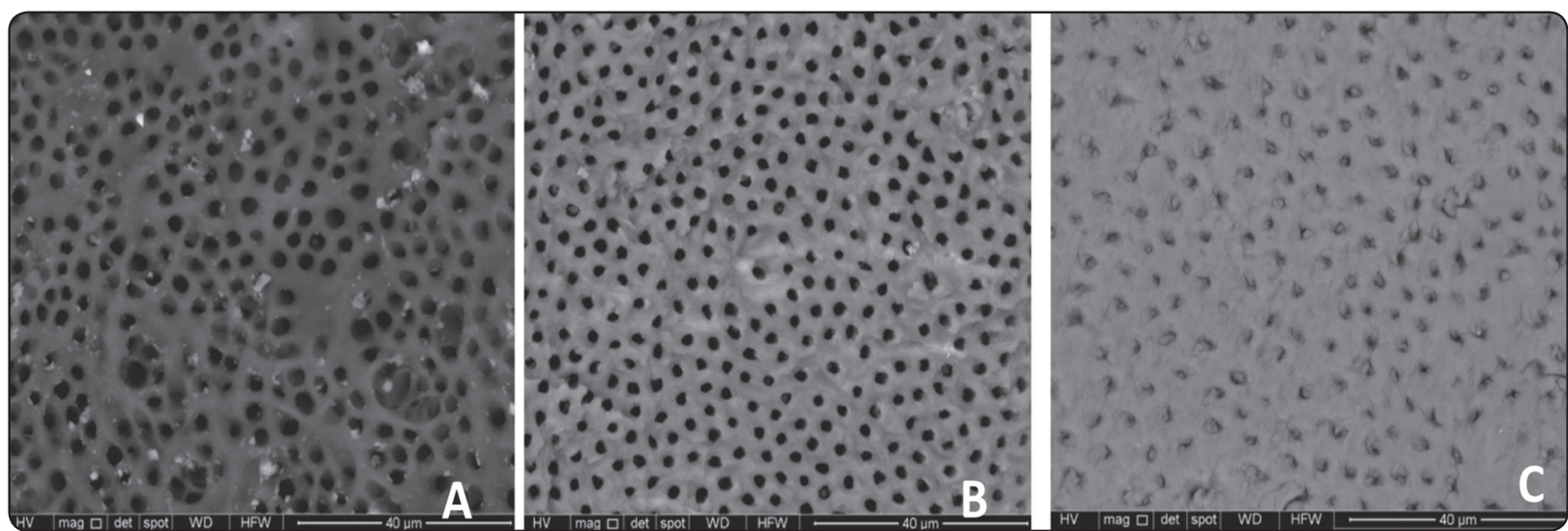

After utilizing the Miswak. Notice the open D.T. after eradication of smear layer on the cervical and medial regions (A) and (B) while the apical region, S.L is still covering most of the dentine tubes (C)
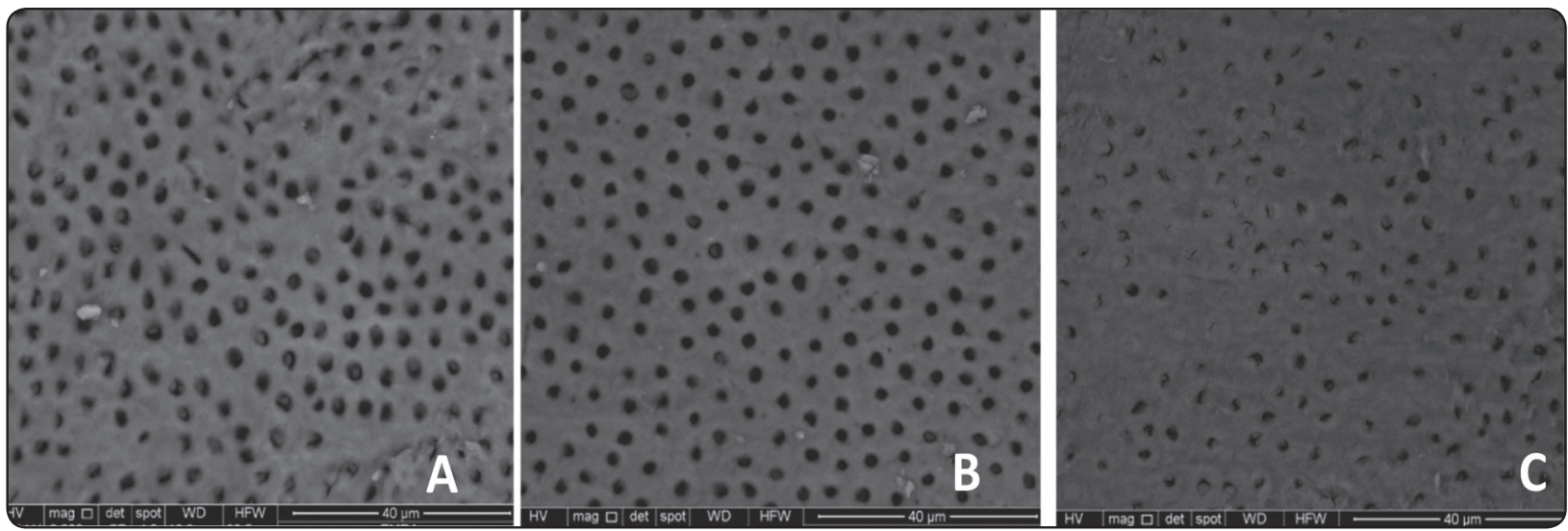

After utilizing chitosan. Notice the patent D.T after eradication of S.L on the cervical and medial regions (A) and (B) while in the apical region, still covering moderate amount $(\mathrm{C})$ 


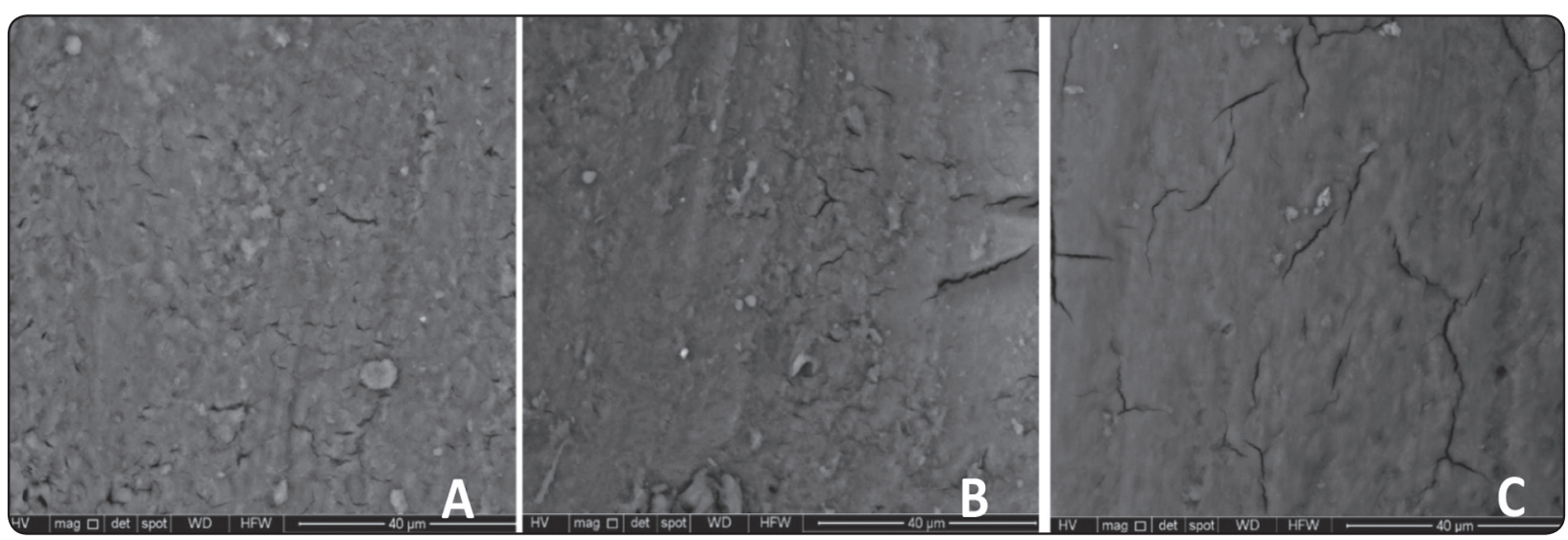

Dentinal tubules completely covered with thick smear layer on coronal, middle and apical thirds after using $5.25 \% \mathrm{NaOCl}$. (A, B\&C).

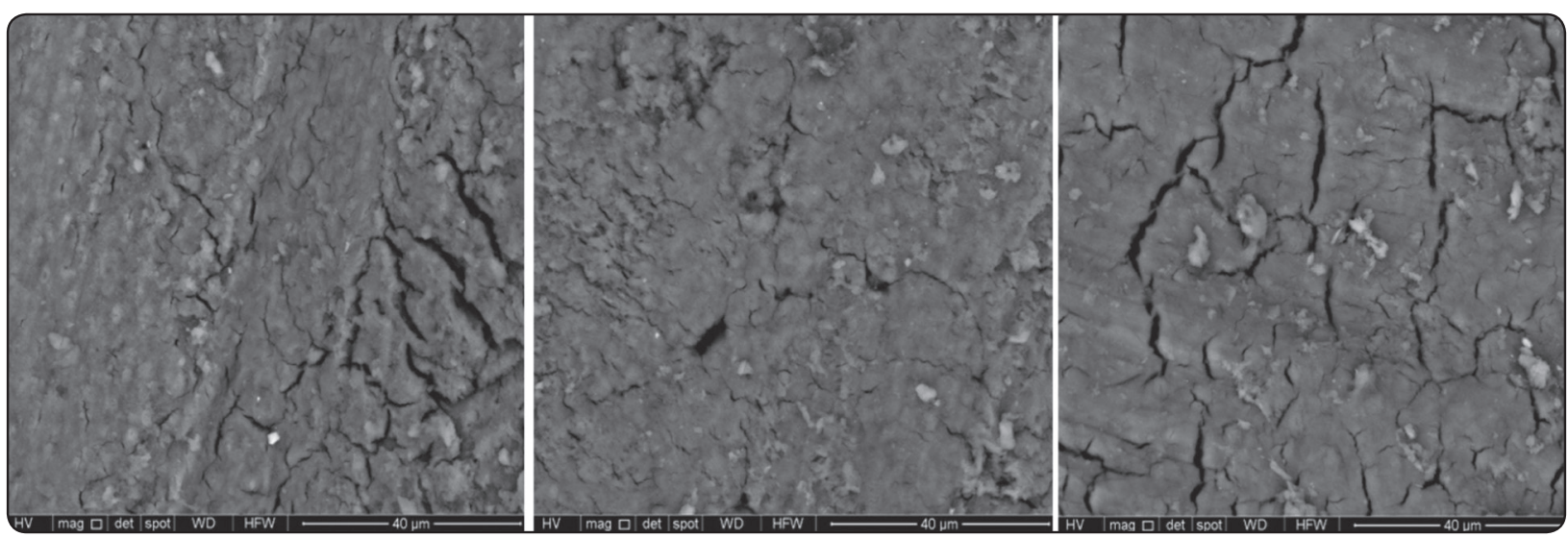

the dentinal tubules completely covered with thick smear layer on coronal, middle and apical thirds after using saline

groups. Also between control positive and $\mathrm{NaOCl}$ groups and both Citosan andSiwak groups. There was no remarkable difference between Chitosan and Miswak groups. Saline and $\mathrm{NaOCl}$ groups showed the highest mean values then Chitosan group, whereas Siwak had the least value.

\section{DISCUSSION}

Successful endodontic treatment depends mainly on proper cleaning and shaping of the root canal complex system. Root canal microorganisms play an important role in development of inflammation and necrosis of the dental pulp, thus periapical disease formation. ${ }^{(11)}$. The principle aim is to totally disinfect this anatomically complex configuration, that dictates the total eradication of its contents as potential well springs of contamination and disease. (12). Different irrigants were utilized during and following mechanical preparation to help eradicate the microorganisms that can't be disposed off by mechanical preparation only due to the root canal anatomical complexities. ${ }^{(13)}$.

The different methods of the root canal preparation result in formation of this coating; comprised of 2 areas: outer most organic layer which is about two microns, then subsequent area stretches out to dentinal tubules to a profundity of 40microns and is to a great extent made of dentin chips. ${ }^{(14)}$ Moreover, achieving clean patent dentinal walls through eradication of this layer is necessary to enhance the smooth hermetic sealing of the entire configuration. ${ }^{(15) .}$ 
The novel $\mathrm{NaOCl}$ was chosen to evaluate the antimicrobial efficiency due to its popularity in the market among endodontists. It has low viscosity allowing easy introduction into the canal architecture, an acceptable shelf life, easily available and inexpensive. ${ }^{(16)}$ By far, it is the gold standard, as it has the unique property of tissue dissolution ability. It reacts with fatty acids and amino acids of the pulp resulting in liquefaction of organic tissues. Also, has a potent bactiricidal potentials against wide range of microorganisms. However, it possess several disadvantages like being tissue irritant, high toxicity to cells, cause dentin collagen denaturation and dissolution, lethal to the progenitor cells at the periapex , foul flavor and may produce allergies and result in hypochlorite accidents. ${ }^{(17)}$

Miswak-Siwak; chewing sticks contain sitosterol beta, m-anisic acis, trimethylamine, sulfadurim chloride and fluoride in large quantities, have shown a great anti-bacterial efficiency without being toxic or irritant to the cell, help in removal of smear layer, allowing it to be one of the promising root canal irrigants that can be an alternative in the near future for the classic $\mathrm{NaOCl}^{(18)}$. It is characterized by being safe and highly bio-compatible ${ }^{(19)}$.

Chitosan;being cheap non-synthetic biocompatible bio-degradable, bio-adherent bipolymer. It improves the mechanical properties of root dentin. Its superior properties along with being non toxic make it a good substitute of the widely used $\mathrm{NaOCl}$ (20). Also, a potent chelator to various minerals, acting on the smear layer aiding to remove $i^{(21)}$.

Enterococcus fecalis; an important pathogen in opportunistic infections in humans as infective endocarditis. It's rarely present in primary apical periodontitis, however they are dominant in root filled teeth with post treatment apical periodontitis. ${ }^{(22)}$. It is also well documented in endodontic infections presenting low sensitivity to conventional treatment ${ }^{(23)}$.Its prevalence in such infections ranges from $30 \%$ to $80 \%$. This finding can be explained by various survival and virulence factors possessed by E. faecalis, including its ability to compete with other microorganisms, invade dentinal tubules, and resist nutritional deprivation ${ }^{(24)}$ Moreover, These microorganisms have the ability to withstand harsh conditions. The ability to tolerate starvation is a hallmark of $\mathrm{E}$. faecalis that can survive until there is an opportunity to obtain adequate nutrition. ${ }^{(25)}$

Moreover, Bile-escullinagar is a unique differential media for presumptive identification of the E.Fecalis and group D streptococci based on the capability of the pathogen to hydrolyze esculin. It contains oxgall (bile salts) that prevent the growth of gram positive pathogens other than them, as it breaks down into dextrose, esculet in interacting with ferric citrate giving the specific media darkening ${ }^{(26)}$, when the pathogen hydrolyze esculin, the media will become dark brown or even black and all performed in sterile environment to avoid infection $^{(27)}$.

Rotary instrumentation was performed in a step-down technique which is superior than the step-back technique, as it decreases the stresses acting on the files during mechanical preparation thus minimizing the possibility of mishaps and instrument separation. Also, early pre-flaring of the coronal part enhance the visibility, and the root canal cleanliness as it acts as a tank of irrigants for better and early entrance into the deeper parts of the canal ${ }^{(28)}$ A remarkable decrease in bacteria was reported with $\mathrm{Ni}-\mathrm{Ti}$ mechanical preparation with a remarkable bacterial count reduction with progressively larger instrument sizes ${ }^{(29) \text {. }}$

Bacteriological procedure was performed by placing absorbent p.p in a passive manner through absorption and in an active manner through instrumentation to avoid inaccurate counting of other microorganisms, while the biofilm pathogens remain protected $^{(30)}$. This sampling technique is characterized by its simplicity and can be easily done at the laboratory, the only drawback is that bacteria only 
present in the lumen can be taken, however those within the dentin tubes couldn't be sampled ${ }^{(31)}$.

Counting of colony formation units (CFUs) was performed because it allowed to calculate the amount of microorganisms inside the root canals. ${ }^{(32)}$ The current study used SEM as an analysis tool to assess the smear layer removal.

Study outcome revealed that $\mathrm{NaOCl}$ had a remarkably greater antimicrobial efficiency compared to both chitosan and Siwak .This may be a reason of the increased levels of the chlorous a. of the $\mathrm{NaOCl}$ that perform apotent antibacterial action through oxidizing the microbial enzymes, which is consistent many other authors. ${ }^{(33)}$.

Also, it was revealed that the antimicrobial efficiency of chitosan and Siwak were remarkably greater than that of the normal saline, that correspond to the earlier studies that concluded that saline can only flush out loose debris however it is absolutely useless and not efficient in terms of an antibacterial irrigant $^{(34) \text {. }}$

Regarding enterococcus fecalis inhibition, $12.5 \%$ Siwak/S.persica was found to be efficient ,however it is of reduced efficiency than that of the potent sodium hypochlorite inhibition .The antibacterial efficiency of Siwak is most probably due to the elevated levels of betatanens, paramethyl-amines, thiocinates, sulphates ${ }^{(35)}$.

The antimicrobial lcapabilities of chitosan is believed to be a result of its unique action when cationically charged amino group interact with the anionic components like $\mathrm{N}$-acetyl muramic acid, sialic acid, and neurmic acid on the microbial membrane, suppressing the microbial growth which results in cell lysis. ${ }^{(36) .}$

Concerning the removal of the smear layer, the outcome revealed that the efficiency of Siwak and chitosan were remarkably greater than the $\mathrm{NaOCl}$ and saline that were also consistent and supported by many other studies ${ }^{(37) .}$
Compounds generated between metallic particles and chitosan may be due to adsorption ,interchange of ions, or chelating action aiding in removal of the inorganic part of the smear layer. ${ }^{(38)}$. Two models have been reported in the literature as possible working mechanisms. One of them, known as the bridge model, is based on the theory that two or more amino groups of the chitosan chain are bound to the same metal ion ${ }^{(39)}$. The other model supports the theory that only one amino group of the substance's structure is involved in binding, namely that the metal ion is "bound" to the amino group (40).

The capability of Siwak to eradicate the smear layer is consistent with the findings of several studies that showed that the alcoholic extract of misiwak caused its disappearance, this can be due to the presence of acid, acting as a chelator for the inorganic part from root dentine ${ }^{(41)}$.

SEM images of sodium hypochlorite survey revealed no surface debris with a smear layer in all one third of the root, indicating $\mathrm{NaOCl}$ inability of $5.25 \%$ in complete removal of the smear layer. These results were similar to Yamada et al. Baumgartner et al. and Vallabhaneni . ${ }^{(42) .}$

It was revealed that, the irrigants demonstrated minimal capabilities on the eradication of smear layer especially those coating the deep inaccessible areas. ${ }^{(43) .}$

\section{CONCLUSION}

Based on the outcomes, the following can be found out: employing of herbal substitutes as irrigants for the root canal may be beneficial given the many adverse effects of the novel sodium hypochlorite. Siwak andChitosan are up and coming in smear layer removal capabilities and promising alternatives for the novel irrigating solutions like sodium hypochlorite and chlorohexidine. Further investigations are required concerning the use of herbal substitutes in endodontics. 


\section{REFRENCES}

1. Goud S, Aravelli S, Dronamraju S, et al. Comparative Evaluation of the Antibacterial Efficacy of Aloe Vera, 3\% Sodium Hypochlorite, and 2\% Chlorhexidine Gluconate Against Enterococcus faecalis: An In Vitro Study. Cureus. 2018; 10(10): e3480

2. Bukhary S, Balto H. Antibacterial Efficacy of Octenisept, Alexidine, Chlorhexidine, and Sodium Hypochlorite against Enterococcus faecalis Biofilms. 2017; 43:643-7.

3. Jhajharia K, Parolia A, Shetty K, Mehta L.Biofilm in endodontics: A review. J Int Soc Prev Community Dent. 2015 Jan-Feb; 5(1): 1-12.

4. Gandolfi MG, Taddei P ,Pondrelli A, Spagnuolo G.Demineralization, Collagen Modification and Remineralization Degree of Human Dentin after EDTA and Citric Acid Treatments. Materials 2019, 12(1), 25

5. Christo JE, Zilm PS, Sullivan T, Cathro PR.Efficacy of low concentrations of sodiumhypochlorite and low-powered Er,Cr:YSGG laseractivated irrigation against anEnterococcusfaecalisbiofilm. Int Endod J. 2016;49: 279-86.

6. Hamedi H, Samuel M.E.Tonelli. Chitosan based hydrogels and their applications for drug delivery in wound dressings: A review. 2018; 199:445-60.

7. Mariem O.Wassela, Mona A.Khattab. Antibacterial activity against Streptococcus mutans and inhibition of bacterial induced enamel demineralization of propolis, miswak, and chitosan nanoparticles based dental varnishes. 2017;8: 387-92.

8. Mohammed.Al-Shahrani, Enrico DiVito, Christopher V. Hughes, Dan Nathanson and George T.: J. Huang Photo Laser Surg. 2014; 1: 32(5): 260-266.

9. A.M. Darrag.: A.M. Effectiveness of different final irrigation solutions on smear layer removal in intraradicular dentin. J Tant Dent. 2014; 93-99.

10. Aksel H, Serper A.Concentration and time-dependent effect of initial sodium hypochlorite on the ability of QMix and ethylenediaminetetraacetic acid to remove smear layer. J Conserv Dent. 2017; 20(3): 185-9.

11. Chow AT, Quah SY, Bergenholtz G, Lim KC, YuVSH, Tan KS.Bacterial species associated with persistentapical peri- odontitis exert differential effects on osteogenicdifferentiation.Int Endod J.2019;52: 201-10.

12. Plotino G, Cortese T, Nicola M. Grande, Denise P. Leonardi. New Technologies to Improve Root Canal Disinfection. 2016; 27:3-8.

13. Barnett F., Siqueira J.F. Instrumentation and Disinfection of Root Canals. Endodontic prognosis, Springer, Cham. 2017; 131-40.

14. Neelakantan, P., Ounsi, H.F., Devaraj, S. et al.Effectiveness of irrigation strategies on the removal of the smear layer from root canal dentin. Odontolog. 2019;107: 142-9.

15. Shahravan A., Haghdoost A.A., Adl A., Rahimi H. and Shadifar F.: Effect of smear layer on sealing ability of canal obturation: a systematic review and meta-analysis. J Endod. 2007;33, 96-105.

16. Patricia P. Wright and Laurence J. Walsh. Optimizing Antimicrobial Agents in Endodontics.2016; 5: 87-108.

17. Saifalarab A. Mohmmed, Morgana E. Vianna, Matthew R. Penny, Stephen T. Hilton, Jonathan C. Knowles . The effect of sodium hypochlorite concentration and irrigation needle extension on biofilm removal from a simulated root canal model. Aust Endod J 2017; 43: 102-9

18. Almas K.: The effect of Salvadora Persica extracts (Miswak) and chlorhexidine gluconate on human dentin: A SEM study. J Contemp Dent Pract. 2002; 3:27-35.

19. Abo Al-Samh, D. and Al-Nazhan, S.: In vitro study of the cytotoxicity of the miswak ethanolic extract. J Saud Dent. 1997; 19, 125-132.

20. Shigenori S., Yoshiko M., Hirobumi M., Yoshishige Y., Hirotaka K. and Takashi M.: The study of chitosan-citrate solution as a root canal irrigant: a preliminary report. J Oral Hyg Health. 2014; 2 (4): 01-04.

21. Josilaine A.P., Danilo Z., Jesus D.P. and Antonio M.C.F.: Chitosan Effect of a new chelating agent on the microhardness of root dentin. J Braz Dent. 2012; 23(3): 212-217.

22. Zandi H, Anne K.Kristoffersen, Isabela N.Rôças, SiqueiraJr F., Enersen M.Microbial Analysis of Endodontic Infections in Root-filled Teeth with Apical Periodontitis before and after Irrigation Using Pyrosequencing. 2018; $44: 372-8$ 
23. Divia A.R. ,Mali G. Nair,Varughese J.M., Kurien S. A comparative evaluation of Morinda citrifolia, green tea polyphenols, and Triphala with $5 \%$ sodium hypochlorite as an endodontic irrigant against Enterococcus faecalis: An in vitro study. 2018;15: 117-22

24. Tabassum S, Khan F.R.Failure of endodontic treatment: The usual suspects. Eur J Dent. 2016 ; 10(1): 144-7.

25. Figdor, D., Davies, J. K. and Sundqvist, G.: Starvation survival, growth and recovery of Enterococcus faecalis in human serum. Oral Micro Immun. 2003; 18: 234-239.

26. Isenberg D. I., Goldberg D. and Sampson J.: Laboratory studies with a selective Enterococcus medium. Appl. Microbiol. 1970; 20: 433-436.

27. Moshari A.A., Akhlaghi N.M., Rahimifard N. and Darmiani S.: Reduction of Enterococcus faecalis in curved root canals after various sizes and tapers of canal preparation. $\mathrm{J}$ Conserv Dent. 2015; 18(4) :306-309.

28. De Souza P.F., Oliveira Goncalves L.C., Franco Marques A.A., Sponchiado Junior E.C., Roberti Garcia L. da F. and de Carvalho F.M.A.: Root canal retreatment using reciprocating and continuous rotary nickel-titanium instruments. J Europ Dent. 2015; 9(2): 234-239.

29. Dalton C.B., Ørstavik D. and Phillips C.: Bacterial reduction with Nickel-Titanium Rotary Instrumentation. J Endod. 1998; 24: 763-767.

30. Warren N., van der Vyver P.G., Botha FS. A comparison of the efficacy of various disinfection protocols in endodontic treatment: An in vitro study. S. Afr. Dent. J.2015; 70: 60-4.

31. Olgart L.G.: Rationalized endodontic treatment by bacteriologic direct sampling technique. J Dent Res. 1970; 49:1427-1430.

32. Isabela N.Rôças, Mônica A.S.Neve, José F.SiqueiraJr. Disinfecting Effects of Rotary Instrumentation with Either $2.5 \%$ Sodium Hypochlorite or 2\% Chlorhexidine as the Main Irrigant: A Randomized Clinical Study.2016;42: 943-7.

33. Cwikla S.J., Belanger M., Giguere S., Progulske-Fox A. and Vertucci F.J.: Dentinal tubule disinfection using three calcium hydroxide formulations. J Endod 2005; 31: 50-52.

34. Wali I.E., Eid G.E.M., Omar W.A. and ElRa E. S.: The An- timicrobial Efficacy of Ozonated Water, Chlorhexidine and Sodium Hypochlorite against Single Species Bio lms of Enterococcus faecalis and Candida albicans. J Egyp Medi Micro. 2008; 17: 419-427.

35. Niazi F, Naseem M, Khurshid Z, Zafar M.S., Almas K.Role of Salvadora persica chewing stick (miswak): A natural toothbrush for holistic oral health.Eur J Dent. 2016 ; 10(2): 301-8

36. Pankaj Y., Sarika C., Rajendra K. Saxena, Sangeeta T. and Sudha Y.: Evaluation of Antimicrobial and Antifungal ef cacy of Chitosan as endodontic irrigant against Enterococcus Faecalis $\square$ and Candida Albicans Biofilm formed on tooth substrate. J Clin Exp Dent. 2017; 9(3): 361-367.

37. Kamble A.B., Abraham S., Kakde D.D., Shashidhar C. and Mehta D.L.: Scanning Electron Microscopic Evaluation of Efficacy of $17 \%$ Ethylenediaminetetraacetic Acid and Chitosan for Smear Layer Removal with Ultrasonics: An in vitroStudy. Contemp Clinical Dent. 2017; 8(4): 621-626.

38. Sakthivel B., Dhakshinamoorthy A. Chitosan as a reusable solid base catalyst for Knoevenagel condensation reaction. 2017;485: 75-80

39. Perochena A.D., Bramante C.M., Hungaro M.A., Regina D.M.. Chelating and antibacterial properties of chitosannanoparticles on dentin. RDE. 2015;40: 195-201

40. Crinia G., CriniaM.N., Rougeb N.F., Déonb S., Fievetb P. Metal removal from aqueous media by polymer-assisted ultrafiltration with chitosan. 2017;10: s3826-39.

41. Balto H., Salama F., Al-Mofareh S. and Al-Yahya F.: Evaluation of Different irrigating solutions on smear layer removal of primary root dentin. J Contemp Dent Pract. 2015;16(3):187-191.

42. Baumgartner J.C., Brown C.M., Mader C.L., Peters D.D. and Shulman J.D.: A scanning electron microscopic evaluation of root canal debridement using saline, sodium hypochlorite and citric acid. J Endodon. 1984; 10: 525531.

43. Wu L., Mu Y., Deng X., Zhang S. and Zhou D.: Comparison of the effect of four decalcifying agents combined with 60 0C $3 \%$ Sodium hypochlorite on smear layer removal. J Endod, 2012; 38(3): 381-384. 